Conner, R. L. \& Wagtendonk, W. J. van (1955). J. gen. Microbiol. 12, 31-36.

\title{
Steroid Requirements of Paramecium aurelia
}

\author{
By R. L. CONNER* aND W. J. VAN WAGTENDONK \\ Department of Zoology, Indiana University, Bloomington, Indiana, U.S.A.
}

\begin{abstract}
SUMMARY: Paramecium aurelia, var. 4, stock 51.7 (s) requires a steroid as a growth factor; $\beta$ - and $\gamma$-sitosterol, fucosterol, brassicasterol, stigmasterol and $\Delta^{4,22}$. stigmastadienone are active in supporting its growth. Esterification of the 3-hydroxyl group decreases the activity. The presence of more than one double bond in the ring system inactivates the molecule, as do the more drastic changes of the side chain, as found in diosgenin, digoxigenin, progesterone, estrone and methyl cholate. Oxidation of the ring system destroys activity. The specificity of these requirements suggests that the steroid functions as an essential metabolite for this organism.
\end{abstract}

Paramecium aurelia, var 4, stock 51.7 (s) has been established in axenic culture in a medium consisting of a yeast extract and proteose peptone, provided a steroid of plant origin is added (van Wagtendonk, Conner, Miller \& Rao, 1953). This steroid, identical with either $\beta$ - or $\gamma$-sitosterol or with a mixture of both sterols, was subsequently isolated from lemon juice (Conner, van Wagtendonk \& Miller, 1953). The observation that no difference between the growth-promoting activities of $\beta$-sitosterol and its optical isomer $\gamma$-sitosterol could be detected, led to a study of the molecular configuration of the steroid molecule, necessary for biological activity for $\boldsymbol{P}$. aurelia. A preliminary report has been published (van Wagtendonk \& Conner, 1953).

\section{METHODS}

Stock cultures of Paramecium aurelia, var. 4, stock 51.7 (s) were maintained at $27^{\circ}$ in a medium consisting of a yeast extract, proteose peptone and lemon juice. The preparation of the yeast extract, and the preparation of the steroid solutions for assay, as well as the assay technique have been previously described (Conner et al. 1953). It should be pointed out here that $\boldsymbol{P}$. aurelia was able to grow at a slow rate in the yeast extract prepared from a few lots of Fleischmann's bakers' yeast (Standard Brands Inc,); in these extracts the active steroids were only stimulatory. The majority of the batches of this yeast yielded extracts in which $\boldsymbol{P}$. aurelia did not grow unless an active steroid was added. Only these batches of yeast extract were used in the survey of the various steroids.

The following steroids were tested in effective concentrations of $800 \mathrm{~m} \mu \mathrm{g}$,, $400 \mathrm{~m} \mu$ g., $200 \mathrm{~m} \mu \mathrm{g} ., 100 \mathrm{~m} \mu \mathrm{g}$. and $50 \mathrm{~m} \mu \mathrm{g} . / \mathrm{ml}$.: cholesterol (U.S.P., Eli Lilly and Co., Indianapolis, Indiana); cholesteryl acetate (Eli Lilly and Co.); epicholesterol, cholestan-3-one, $\Delta^{4}$-cholesten-3-one (gifts from Dr C. C. Stock, Sloan Kettering Institute for Cancer Research, and from Dr Helen S. Vishniac,

* Predoctoral Fellow of the National Science Foundation (1952-4). Present address: Bryn Mawr College, Bryn Mawr, Pennsylvania, U.S.A. 
Department of Microbiology, Yale University); $3 \boldsymbol{\beta}$-cholestanol (three samples respectively from Dr Stock, Dr Vishniac, and from Eli Lilly and Company); 25-keto-norcholestanyl acetate, cerebrosterol, cerebrostenolone, 25-ketonorcholesteryl acetate, coprosterol (Dr H. S. Vishniac); zymosterol (Fleischmann Laboratories through the courtesy of Dr O. N. Breivik); 24-keto cholesterol (Sloan Kettering Institute); 7-keto-cholesteryl acetate (Lederle Laboratories through the courtesy of Dr S. Bernstein); lanost-7-ene-3-ol acetate, lanosta-3-ol acetate, lanost-8-ene-3-ol acetate, lanosta-7, 9(11)-diene3-ol acetate, lanosta-5, 7-diene-3-ol (gifts of Dr D. H. R. Barton, Birkbeck College, London); ergosterol (Eli Lilly and Co., Dr Barton); $\Delta^{8(9), 22}$-ergostadiene11-one-3 $\beta$-ol-3-acetate, neoergosterol (Eli Lilly and Co.); ergostanyl acetate, $\beta$-ergostenol, $\Delta^{7}$-ergostenol, $\gamma$-dihydroergosterol, ergostanol, ergostane (Lederle Laboratories); ergostenol D acetate, $3 \beta$-acetoxy-cerevisterol, cerevisterol, $3 \beta$-acetoxy-5 $\alpha$-hydroxyergosta-7, 9(11), 22-triene, ergosterol $\mathrm{B}_{3}$ acetate, $3 \beta$-acetoxy-5 $\alpha$-hydroxyergosta-7, 22-diene, $3 \beta$-6 $\beta$-diacetoxycerevisterol, ergosterol $B_{1}, 3 \beta$-acetoxy-5 $\alpha$-hydroxyergosta-8(14)-ene (Dr D. H. R. Barton); brassicasterol, 5-dihydroergosterol (Dr H. S. Vishniac); brassicasteryl acetate, neospongosteryl acetate, chalinasterol, a mixture of stellasterol and stellastenol (Dr W. Bergman, Sterling Chemistry Laboratories, Yale University); $\beta$-sitosterol (three samples from Dr H. S. Vishniac, one sample from Dr S. Bernstein); fucosterol (Dr H. S. Vishniac); $\gamma$-sitosterol, poriferasterol (Dr W. Bergman); $\alpha$-spinasterol (one sample from Dr W. Bergman, one sample from Eli Lilly and Co.); stigmasterol, stigmasteryl acetate (Eli Lilly and Co.); stigmastanyl acetate (Lederle Laboratories); $\alpha$-spinastenol (Dr D. H. R. Barton), $\Delta^{4,22}$-stigmastadienone (Upjohn Co., through the courtesy of Dr A. C. Ott); chondrillasterol (Merck and Co., through the courtesy of Dr W. J. McAleer); progesterone, estrone, desoxycorticosterone, digoxigenin (Sloan Kettering Institute); methyl cholate, diosgenin (Eli Lilly and Co.); Windaus's keto acid (Dr H. S. Vishniac). The samples were recrystallized several times before use whenever possible. In some cases, however, the amounts available were too small to allow recrystallization, and these compounds were tested as received.

\section{RESULTS}

The following steroids and their derivatives were found to be active:

$\beta$-sitosterol, clionasterol ( $\gamma$-sitosterol), fucosterol, brassicasterol, stigmasterol, poriferasterol, brassicasteryl acetate, stigmasteryl acetate and $\Delta^{\mathbf{4}{ }^{22} \text { - }}$ stigmastadienone (Figs. 1 and 2). It can be seen from Fig. 1 that the same population density was reached with the two sitosterols and fucosterol. When stigmasterol, poriferasterol or $\Delta^{4,22}$-stigmastadienone were substituted for the sitosterols a 10 times higher population density was obtained. The response of Paramecium aurelia to the addition of brassicasterol was intermediate to that of the sitosterol and the stigmasterol group.

The response of Paramecium aurelia to increasing concentrations of stigmasterol and stigmasteryl acetate, and brassicasterol, and its acetate are given in Fig. 2. The acetates, at low concentrations, were less efficient in promoting 
the growth of $\boldsymbol{P}$. aurelia. At higher concentrations the growth-promoting activity of stigmasteryl acetate and brassicasteryl acetate approached that of the corresponding free sterols.

None of the other steroids tested showed any growth-promoting activity for Paramecium aurelia.

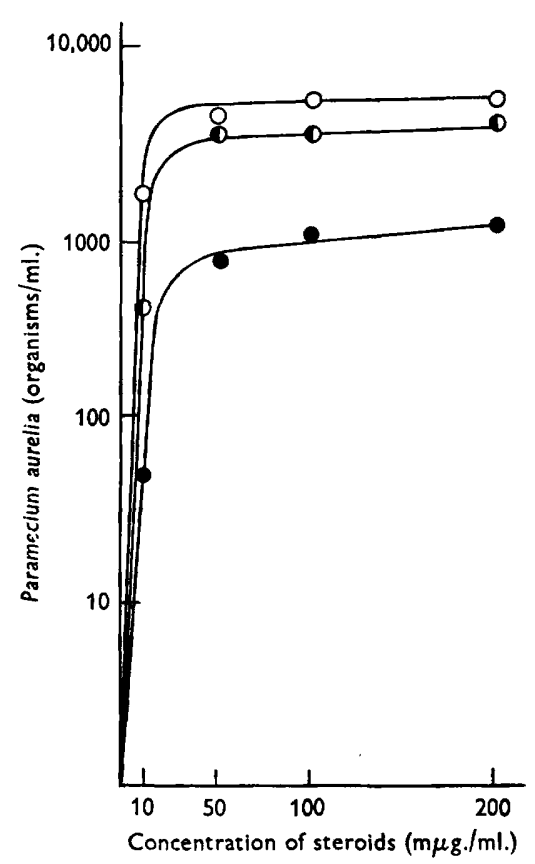

Fig. 1

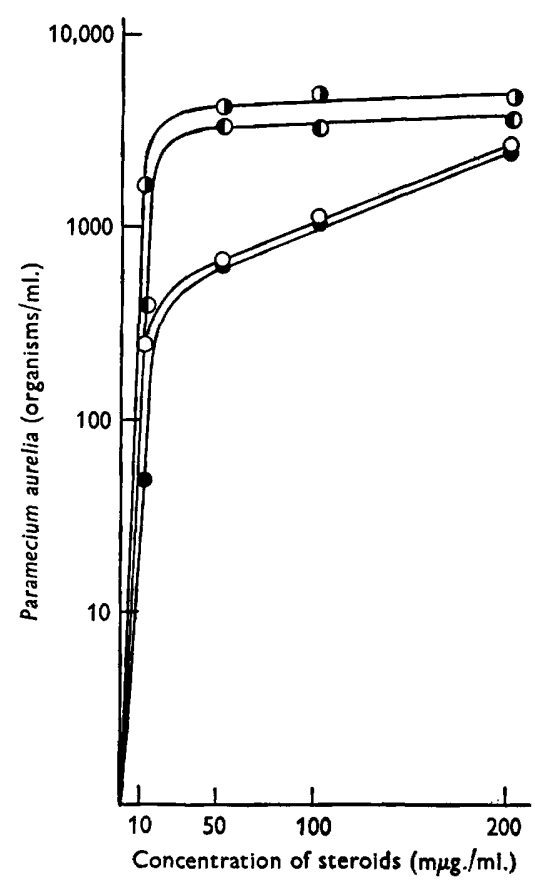

Fig. 2

Fig. 1. Growth response of Paramecium aurelia, var. 4, stock $51 \cdot 7$ (s) in axenic culture to increasing concentrations of the sitosterol group (O); brassicasterol ( $(0)$; stigmasterol, poriferasterol, or $\Delta^{4,22}$ stigmastadienone (O).

Fig. 2. Growth response of Paramecium aurelia, var. 4, stock 51.7 (s) in axenic culture to increasing concentrations of : stigmasterol ( $\odot$ ); stigmasteryl acetate $(\odot)$; brassicasterol (D); brassicasteryl acetate $(O)$.

\section{DISCUSSION}

A comparison of the structures of active and inactive steroids leads to the following conclusions:

(1) Steroids having the cholesterol configuration are inactive.

(2) Addition of either an ethyl-or vinyl group at $\mathrm{C}_{24}$ imparts activity to the molecule, since the sitosterols and fucosterol are active.

(3) Optical isomerism at $\mathrm{C}_{24}$ does not influence the activity, $\beta$ - and $\gamma$-sitosterol, and stigmasterol and poriferasterol are equally active.

(4) Unsaturation of the side chain at $\mathrm{C}_{22,23}$ enhances the activity; stigmasterol, poriferasterol, and $\Delta^{\mathbf{4}, 22}$-stigmastadienone are more active than the sitosterols.

(5) It seems probable that the addition of a methyl group at $\mathrm{C}_{24}$ also imparts activity to the steroid molecule, since brassicasterol is active. It could not be 
established whether the addition of the methyl group by itself is sufficient for growth-promoting activity (like the addition of an ethyl group) or whether the addition of a double bond at $\mathrm{C}_{22,23}$ is also necessary. The compound which would establish this point, ergosta-5-ene-3 $\beta$-ol was not available for testing.

(6) Saturation of all the double bonds destroys activity, as testified by the inactivity of ergostanol and stigmastanyl acetate.

(7) The presence of a second double bond in the ring system inactivates the molecule. Ergosterol, ergosta-8(9), 14, 22-triene-3 $\beta$-ol (ergosterol $B_{1}$ ), ergosta-7, $9(11)$, 22-triene-3 $\beta$-ol acetate (ergosterol D acetate), and ergosta-7, 14, 22-triene-3 $\beta$-ol acetate (ergosterol $B_{3}$ acetate) were all inactive.

(8) Esterification of the 3-hydroxyl group lowers the activity (Fig. 2).

(9) Oxidation of the 3-hydroxyl group to a ketone group and the simultaneous rearrangement of the double bond from $\mathrm{C}_{5,6}$ to $\mathrm{C}_{4,5}$ does not affect the activity since $\Delta^{4,22}$-stigmastadienone is as active as stigmasterol.

(10) Degradation of the side chain destroys activity. Progesterone, testosterone, methyl cholate and desoxycorticosterone are all inactive.

(11) Changing the side chain of the steroid molecule to that of a saponin or of a cardiac aglycone results in inactivity of the molecule, since disogenin and digoxigenin are inactive.

(12) The 5:6 double bond appears to be essential for activity, although some doubt exists concerning this point. Ergost-7-ene-3 $\beta$-ol ( $\Delta^{7}$-ergosterol) is inactive, while stigmast-7-ene- $3 \beta$-ol ( $\alpha$-spinastenol) is active. It is possible that either or both of these two samples was contaminated. The growthpromoting activity of stigmast-7-ene-3 $\beta$-ol may have been due to a contaminant with growth-promoting activity (stigmasterol) or the ergost-7ene- $3 \beta$-ol could have been contaminated with a toxic compound.

At present only a few micro-organisms and one mammalian species are known to require exogenous steroids for growth. The studies of Cailleau $(1937,1938 a, b, 1939)$ indicated a true metabolic requirement for steroids for Trichomonas columbae, $T$. foetus, Eutrichomastix colubrorum and Trichomonas batrachorum. Vishniac \& Watson (1953) studied the steroid requirements of the myxothallophyte Labyrinthula vitellina var. pacifica. The other microorganisms which require steroids are organisms of the pleuropneumonia group (Edward \& Fitzgerald, 1951), and Peranema trichophorum (Storm \& Hutner, 1953). Ross, van Wagtendonk \& Wulzen (1949) and van Wagtendonk \& Wulzen (1951) reported that a steroid, later identified as stigmasterol (Kaiser \& Wulzen, 1951), functioned as an essential metabolite for guinea-pigs. The specificity requirements for these organisms vary widely, as is evident from Table 1.

It is difficult to draw definite conclusions because of the many gaps in the table. A comparison can be made between the specificity requirements of the two organisms which have been most intensively investigated, Labyrinthula vitellina and Paramecium aurelia. The similarities between the specificity requirements are the following: (1) the oxidation of the 3-OH group does not affect activity; (2) the presence of more than one double bond in the ring structure inactivates the steroid; (3) degradation of the side chain, or changing 
the character of the side chain also inactivates the molecule. The differences between the specificity requirements are striking: (1) the presence of an ethyl group, a vinyl group or a methyl group (?) is essential for activity in the case of $\boldsymbol{P}$. aurelia, while it is not for Labyrinthula vitellina; (2) esterification of the 3-OH group lowers the activity of the steroid for Paramecium aurelia, while such a treatment completely inactivates the compound for Labyrinthula vitellina; (3) unsaturation of the side chain at $\mathrm{C}_{22,23}$ enhances the activity of the steroid for Paramecium aurelia, while it inactivates the same compound for

Table 1. A comparison of the growth-promoting activity of various steroids $+=$ active $;-=$ inactive; . = not tested.

\begin{tabular}{|c|c|c|c|c|c|c|}
\hline $\begin{array}{l}\text { Tricho- } \\
\text { monas } \\
\text { columbae }\end{array}$ & $\begin{array}{l}\text { Labyrin- } \\
\text { thula } \\
\text { vitellina }\end{array}$ & $\begin{array}{c}\text { Peranema } \\
\text { tricho- } \\
\text { phorum }\end{array}$ & $\begin{array}{c}\text { Para- } \\
\text { mecium } \\
\text { aurelia }\end{array}$ & $\begin{array}{l}\text { Trichomonas } \\
\text { foetus } \\
\text { T. batra- } \\
\text { chorum } \\
\text { Eutricho- } \\
\text { mastix } \\
\text { colubrorum }\end{array}$ & $\begin{array}{c}\text { Guinea- } \\
\text { pig }\end{array}$ & $\begin{array}{c}\text { Pleuro- } \\
\text { pneumonia- } \\
\text { like } \\
\text { organisms }\end{array}$ \\
\hline+ & + & + & - & + & - & + \\
\hline+ & + & + & + & . & + & . \\
\hline . & - & . & + & . & + & • \\
\hline . & + & . & + & • & + & • \\
\hline . & - & + & + & . & + & + \\
\hline . & . & + & + & . & . & . \\
\hline . & - & + & + & . & . & . \\
\hline+ & - & + & - & . & . & • \\
\hline . & - & . & - & . & . & . \\
\hline . & - & . & - & . & . & • \\
\hline
\end{tabular}

Labyrinthula vitellina. The evidence suggests that the active steroids are not themselves the essential metabolite but precursors for it. This essential metabolite will not be one of the steroids which the cells contain in such great variety and in relatively large quantities, but will be a steroid present in only trace amounts which have hitherto escaped detection. These steroids probably function in a variety of organisms as a cofactor for some essential metabolic process, although it does not necessarily follow that the essential metabolite be the same for each organism tested.

The authors wish to express their gratitude to those (indicated in the text) who so generously donated the steroids used in this investigation. This work was carried out under the auspices of a grant from Eli Lilly and Co., a grant from the National Cancer Institute of the National Institutes of Health (No. C-2160 (C)-), and grants from the Rockefeller Foundation and Indiana University. Partly based on a thesis presented by the senior author in partial fulfilment of the requirements for the Ph.D. degree by the Indiana University. This paper is contribution no. 485 from the Department of Zoology, Indiana University. 


\section{REFERENCES}

CaIlleau, R. (1937). La nutrition des flagellés tétramitidés. Les stérols, facteurs de croissance pour les trichomonades. Ann. Inst. Pasteur, 59, 137.

CaIlleau, R. (1938a). Le cholestérol et l'acide ascorbique, facteurs de croissance pour le flagellé tétramitidé Trichomonas foetus Riedmuller. C.R. Soc. Biol., Paris, 127, 861.

Cailleau, R. (1938b). L'acide ascorbique et le cholestérol, facteurs de croissance pour le flagellé Eutrichomastix colubrorum. C.R. Soc. Biol., Paris, 127, 144.

CaIlleau, R. (1939). Le cholestérol, facteur de croissance pour le flagellé Trichomonas batrachorum. C.R. Soc. Biol., Paris, 130, 1089.

Conner, R. L., Wagtendonk, W. J. van \& Miller, C. A. (1953). The isolation from lemon juice of a growth factor of steroid nature required for the growth of a strain of Paramecium aurelia. J. gen. Microbiol. 9, 434.

Edward, D. G. ff. \& Fitzgerald, W. A. (1951). Cholesterol in the growth of organisms of the pleuropneumonia group. J. gen. Microbiol. 5, 576 .

KAISER, E. \& WulzeN, R. (1951). Identification of a sugar-cane sterol antistiffness factor as stigmasterol. Arch. Biochem. 31, 326.

Ross, L. E., Wagtendonk, W. J. van \& Wulzen, R. (1949). Evidence for a steroid compound in cane juice possessing antistiffness activity. Proc. Soc. exp.Biol., N.Y. 71, 281.

Storm, J. \& Hutner, S. H. (1953). Nutrition of peranema. Ann. N.Y. Acad. Sci. $56,901$.

VishNiaC, H. S. \& Watson, S. W. (1953). The steroid requirements of Labyrinthula vitellina var. pacifica. J. gen. Microbiol. 8, 248.

Wagtendonk, W. J. van \& Conner, R. L. (1953). Steroid requirements for Paramecium aurelia, var. 4, stock 51.7 (s) in axenic culture. Fed. Proc. 12, 283.

Wagtendonk, W. J. van, Conner, R. L., Mrller, C. A. \& Rao, M. R. R. (1953). Growth requirements of Paramecium aurelia, var. 4, stock 51.7, sensitives and killers in axenic medium. Ann. N.Y. Acad. Sci. 56, 929.

Wagtendonk, W. J. van \& Wulzen, R. (1951). Physiological and chemical aspects of the antistiffness factor essential for guinea pigs. Vitamins and Hormones, 8 , 69.

(Received 21 July 1954) 